\title{
Chronic toxicity of silver nanoparticles to Daphnia magna under different feeding
} conditions

\author{
Mackevica, Aiga; Skjolding, Lars Michael; Gergs, Andre; Palmqvist, Annemette; Baun, Anders
}

Published in:

Aquatic Toxicology

Link to article, DOI:

10.1016/j.aquatox.2015.01.023

Publication date:

2015

Document Version

Peer reviewed version

Link back to DTU Orbit

Citation (APA):

Mackevica, A., Skjolding, L. M., Gergs, A., Palmqvist, A., \& Baun, A. (2015). Chronic toxicity of silver nanoparticles to Daphnia magna under different feeding conditions. Aquatic Toxicology, 161, 10-16. https://doi.org/10.1016/i.aquatox.2015.01.023

\section{General rights}

Copyright and moral rights for the publications made accessible in the public portal are retained by the authors and/or other copyright owners and it is a condition of accessing publications that users recognise and abide by the legal requirements associated with these rights.

- Users may download and print one copy of any publication from the public portal for the purpose of private study or research.

- You may not further distribute the material or use it for any profit-making activity or commercial gain

- You may freely distribute the URL identifying the publication in the public portal 
Chronic toxicity of silver nanoparticles to Daphnia magna under different

\section{feeding conditions}

Aiga Mackevica* ${ }^{\dagger}$, Lars Michael Skjolding $^{\dagger}$, Andre Gergs $^{\ddagger}$, Annemette Palmqvist $^{\ddagger}$, Anders Baun $^{\dagger}$

${ }^{\dagger}$ Technical University of Denmark, Department of Environmental Engineering, Miljøvej,

Building 113, DK-2800 Kgs. Lyngby, Denmark.

${ }^{\ddagger}$ Roskilde University, Department of Environmental, Social and Spatial Change,

Universitetsvej 1, P.O. Box 260, DK-4000 Roskilde, Denmark.

*Corresponding author: aima@env.dtu.dk 


\begin{abstract}
Despite substantial information on the acute toxicity of silver nanoparticles (AgNP) to aquatic organisms, little is known about their potential chronic effects and the applicability of current test guidelines for testing nanomaterials. The purpose of this study was to study the influence of food availability on toxicity. This was done through a series of Daphnia magna 21-day reproduction tests (OECD 211) using $30 \mathrm{~nm}$ citric acid stabilized AgNP aimed at studying the influence of food abundance on the reproductive toxicity of AgNP in D. magna. The experiments were carried out as static renewal tests with exposure concentrations from 10 to $50 \mu \mathrm{gg} / \mathrm{L}$, and test animals were fed green algae Pseudokirchneriella subcapitata in low and high food treatments. The endpoints recorded were survival, growth of parent animals and number of live neonates produced. Detrimental effects of AgNP on survival, growth and reproduction were observed in concentrations higher than $10 \mu \mathrm{g} \mathrm{Ag} / \mathrm{L}$, whereas the animals exposed to 10 $\mu \mathrm{g} \mathrm{Ag} / \mathrm{L}$ had larger body length and produced more offspring than controls at both food treatments. High food treatment resulted in higher animal survival, growth and reproduction compared to result found for low food treatment.
\end{abstract}

Keywords - AgNP; Nanomaterials; Reproduction; Nanoecotoxicology 


\section{Introduction}

Silver is used in a wide range of applications due to its antimicrobial properties, and in recent years the use of silver in nanoparticle form has dramatically increased (Moore, 2006). Data from year 2013 show that silver nanoparticles (AgNP) have become the dominant engineered nanoparticles used in consumer products (The Project on Emerging Nanotechnologies, 2013). The increasing use of nanosilver-containing products may lead to higher silver emissions into the environment, which raises concern about environmental implications (Elzey and Grassian, 2010, Hoheisel et al., 2012). Different forms of silver can have negative impacts on aquatic ecosystems by causing toxic effects to aquatic organisms (Shafer et al., 1998, Hoheisel et al., 2012). While a substantial number of studies describe the lethal toxicity of various forms of silver, including silver nitrate $\left(\mathrm{AgNO}_{3}\right)$ and silver nanoparticles (AgNP) (Allen et al., 2010, Hoheisel et al., 2012, Kennedy et al., 2010), the information on chronic toxicity to aquatic organisms is scarce. Also the mechanisms of nanosilver toxicity are poorly understood. There is an ongoing debate regarding the modes of toxicity and the contribution of silver ions to toxic effects (Poynton et al., 2012).

To the best of our knowledge, there are only four studies published regarding reproductive toxicity of AgNP to D. magna (Zhao and Wang, 2011, Pokhrel and Dubey, 2012, Gaiser et al., 2011, Blinova et al., 2013). Some papers state the necessity of chronic studies for better understanding of AgNP toxicity, but they also note that such studies are both time consuming and expensive (Gaiser et al., 2012, Zhao and Wang, 
2011). Blinova et al. (Blinova et al., 2013) investigated how different coatings and test media affect AgNP toxicity, using polyvinylpyrrolidone (PVP) and collargol coated particles, and natural river and lake water as media. River water had a high content (35 $\mathrm{mg} \mathrm{C/L}$ ) of dissolved organic carbon (DOC). No sub-lethal effects were observed for both types of AgNP, but daphnids exposed to AgNP in lake water $(5.3 \mathrm{mg} \mathrm{C} / \mathrm{L}$ ) showed significant decrease in reproduction rates at $100 \mu \mathrm{g} / \mathrm{L}$. The varying toxicity is most likely attributed to the difference in DOC concentrations (Blinova et al., 2013), as DOC and other organic components in natural water can substantially influence silver speciation, toxicity and bioavailability to aquatic organisms (Bianchini and Wood, 2008, Ratte, 1999). Zhao and Wang (Zhao and Wang, 2011) also observed decrease in reproduction when daphnids were exposed to $50 \mu \mathrm{g} \mathrm{Ag} / \mathrm{L}$. They used carbonate coated AgNP in simplified M7 medium, and added cysteine to form complexes with $\mathrm{Ag}^{+}$ions. As addition of cysteine did not lower the toxicity, Zhao and Wang attributed the reproductive effects found to silver in NP form (Zhao and Wang, 2011). Lower exposure concentrations of AgNP (1-2 $\mu \mathrm{g} \mathrm{Ag} / \mathrm{L})$ have been reported to increase body length (Gaiser et al., 2011) and reproduction of daphnids (Pokhrel and Dubey, 2012).

The documented AgNP toxic effects show high interstudy variability, which may be partly explained by differences in particle size and surface functionality, test media or other parameters. For example, it has been reported that AgNP acute toxicity (48-h EC50) can be multiple times lower when DOC is present in the media (Blinova et al., 2013, Cupi et al., (in press)) or when food is applied during testing (Allen et al., 2010). In 
addition, the influence of DOC content on AgNP chronic toxicity (21-d) was addressed in the study by Blinova et al (Blinova et al., 2013) showing a higher toxicity of AgNP with lower content of DOC. In the study by Allen et al. (Allen et al., 2010) food availability during AgNP exposure was found to alter results from acute toxicity testing. Variations in food abundance have been shown to markedly influence the fitness of $D$. magna in the absence of any toxicants (Martínez-Jerónimo et al., 1994, Porter et al., 1983). Overexploitation of resources, resulting from intraspecific competition, was observed to result in reduced survival, growth and fecundity (Miller, 1967). These resource-related mechanisms may contribute to periodic fluctuations in resource-consumer interactions that are frequently observed in both laboratory settings and natural systems (McCauley and Murdoch, 1987, McCauley et al., 1999). Fluctuations in consumer density can result in transient periods of low or high food availability that might interfere with AgNP toxicity.

The purpose of this study was, therefore, to elucidate the influence of food availability on AgNP toxicity to D. magna. We considered two food conditions: low food (as suggested by OECD guideline nr. 211 (Organisation for Economic Co-operation and Development, 2012)) and high food (three times the amount applied for low food conditions). The endpoints of interest were survival for 48 hour acute toxicity tests, and survival, cumulative offspring and growth of the parent daphnids for 21 day chronic toxicity tests. D. magna was selected as the test subject because it is very sensitive to silver (Ratte, 1999) and widely recognized as a well-established test organism in 
ecotoxicology due to its ecological importance, ease of culturing, and short life span (Roemer et al., 2011). Along with other filter feeders present in zooplankton, it is an important link in the aquatic food web and can therefore have an influence on species at higher trophic levels (Baun et al., 2008).

\section{Materials and methods}

Organisms, medium, and chemicals

D. magna culture was maintained in modified Elendt M7 medium (with double amount of trace elements and ten times higher concentration of $\mathrm{KCl}$ compared to $\mathrm{OECD}$ recipe (Organisation for Economic Co-operation and Development, 2012)) and held in $1 \mathrm{~L}$ beakers at a density of one individual per $100 \mathrm{~mL}$. The culture was kept in a $20{ }^{\circ} \mathrm{C}$ climate controlled room with 16:8 hour light:dark cycle. Animals in the stock culture were fed with green algae Pseudokirchneriella subcapitata three times a day by automatic pump. The algae for feeding were cultured in $20^{\circ} \mathrm{C}$ and harvested when reaching a cell density of around $10^{6}$ to $10^{7}$ cells $/ \mathrm{ml}$. For acute and chronic tests that involved feeding the animals, the algal suspension was concentrated by settling at $4{ }^{\circ} \mathrm{C}$ for 3 to 4 days and the settled biomass was used for feeding after removing the excess medium. For chronic tests a fresh algal suspension was prepared weekly. The algal cell density was determined by Z2 Coulter Counter® (by Beckman Coulter) and the carbon content was calculated using the previously reported correlation where $10^{4}$ cells $/ \mathrm{mL}$ equals about $0.1 \mathrm{mg} \mathrm{C/L}$ (Hailing-Sørensen et al., 1996). In all toxicity experiments, the 
daphnids used were $<24$ hour old neonates (first brood was not used). Modified Elendt M7 medium was used for all tests and prepared according to OECD guideline 211 (Organisation for Economic Co-operation and Development, 2012).

Commercially available citric acid coated AgNP were purchased from Cline Scientific AB, Gothenburg, Sweden. The particles were suspended in Milli-Q water and had a reported diameter of $30 \mathrm{~nm}$. The nominal concentration according to manufacturer was $20 \mathrm{mg}$ $\mathrm{Ag} / \mathrm{L}$, which was confirmed by Inductively Coupled Plasma - Optical Emission Spectroscopy (ICP-OES) measurements. The particle suspensions were kept at $4{ }^{\circ} \mathrm{C}$ in the dark, and used in toxicity tests without prior sonication.

\subsection{Chemical analysis and characterization}

The total Ag concentration in the AgNP stock suspension and test suspensions before adding algae or daphnids was analyzed using ICP-OES (Varian Vista-MPX CCD simultaneous ICP-OES). The samples were digested in $16 \% \mathrm{HNO}_{3}$ for $24-\mathrm{h}$ at room temperature in the dark, then diluted with deionized water (DIW) and kept at room temperature in the dark until analysis.

Mass balance analysis was carried out for an exposure concentration of $40 \mu \mathrm{g} / \mathrm{L}$ by simulating the chronic test experimental setup described below. Five beakers for each food treatment were prepared, adding an adult daphnid ( $>3$ weeks old) to each beaker. After three days test animals were removed from the beakers with a mesh, dipped in 
clean water and digested with concentrated nitric acid (65\%). The content of the beaker was stirred and collected for analysis. The beakers were then carefully washed with concentrated nitric acid to remove the silver adsorbed to the glass. Samples were analyzed by ICP-OES.

The content of dissolved Ag was tested by preparing AgNP suspension in M7 medium, leaving it for $72 \mathrm{~h}$ (to simulate the longest time between changing the media in the chronic test setup), and then separating particulate and dissolved $\mathrm{Ag}$ by ultracentrifugartion (Beckman Coulter L8-60M). The suspensions were prepared in 6 replicates and spun at $3 \times 10^{4} \mathrm{rpm}(154049 \mathrm{~g})$ for 20 minutes. Subsequently, the supernatants were removed, acidified with nitric acid, and analyzed by ICP-MS (Agilent 7700x).

Before toxicity testing, the particle size and zeta potential in stock suspension and AgNP suspensions in M7 medium was characterized by ZetaSizer Nano ZS (by Malvern Instruments Ltd). Additionally, samples of AgNP stock solution and AgNP suspensions in M7 medium were examined by transmission electron microscope Tecnai T20 $\mathrm{G}^{2}$ (by FEI). Samples were prepared by placing $4 \mu \mathrm{L}$ of suspension on a copper grid covered with carbon film (by Agar Scientific), which was then left at room temperature for around 4 hours for water to evaporate.

\subsection{Acute toxicity tests}


The 48 hour acute toxicity testing was carried out following the OECD Guideline 202 (Organisation for Economic Co-operation and Development, 2004) using freshly prepared, oxygen saturated $\mathrm{M} 7$ medium and $\mathrm{pH}$ ranging from 8.2 to 8.6. $\mathrm{AgNO}_{3}$ was used as reference compound for the acute toxicity tests. Three 48 hour acute tests were performed with AgNP and D. magna ( $<24 \mathrm{~h}$ old): one with no feeding and, deviating from the guideline, two with feeding (low and high food levels $-2.4 \times 10^{5}$ cells $/ \mathrm{mL}$ and $7.2 \times 10^{5}$ cells $/ \mathrm{mL}$, respectively). The exposure concentrations were $10,25,50,75,100$, 150 and $200 \mu \mathrm{g} \mathrm{Ag} / \mathrm{L}$ for the test with no added food, and 25, 50, 100, 150, 200, 250 and $300 \mu \mathrm{g} \mathrm{Ag} / \mathrm{L}$ for tests with low and high food levels. The beakers were kept in a $20{ }^{\circ} \mathrm{C}$ temperature controlled room in the dark and immobility was recorded after 24 and 48 hours.

\subsection{Chronic toxicity tests}

Three chronic tests were performed - one with $\mathrm{AgNO}_{3}$ as a reference test with low food conditions, and two with AgNP with low and high food conditions. The chronic tests were set up following the OECD 211 Guideline (Organisation for Economic Co-operation and Development, 2012). The test animals were $<24$-h old D. magna neonates and all the test suspensions were prepared with freshly prepared, oxygen saturated M7 media with $\mathrm{pH}$ ranging from 8.2 to 8.6. During testing, animals were maintained individually, each in a $100 \mathrm{~mL}$ glass beaker with $50 \mathrm{~mL}$ of test suspension, each exposure treatment and control having 10 replicates. Exposure concentrations were $0.25,0.5,1.0$ and $1.6 \mu \mathrm{g}$ $\mathrm{Ag} / \mathrm{L}$ for test with $\mathrm{AgNO}_{3}$ and 10, 20, 30, 40 and $50 \mu \mathrm{g} \mathrm{Ag} / \mathrm{L}$ for tests with AgNPs. Parent 
animals were transferred to new beakers three times per week by using a clean plastic mesh. The beakers were kept in a $20{ }^{\circ} \mathrm{C}$ temperature controlled room with a $16: 8-\mathrm{h}$ light:dark cycle. The daphnids were fed every day using concentrated algae suspensions with amounts resulting in $2.4 \times 10^{5}$ cells $/ \mathrm{mL}$ and $7.2 \times 10^{5}$ cells $/ \mathrm{mL}$ concentrations for low and high food treatments, respectively.

Mortality of the test animals and production of live offspring was recorded daily. The neonates were removed from the test suspension to prevent them from consuming the food intended for the parent animal. Body length, excluding spina, was digitally measured under magnification on day 0, 5, 9, 14 and 21.

\subsection{Data treatment}

The 48 hour acute toxicity (48-h EC50) and $95 \%$ confidence intervals were calculated by using logistic curve fitting with inverse estimation, assuming a log-normal distribution (Christensen et al., 2009). For chronic toxicity, data were expressed as mean \pm standard deviation. Statistical analyses were carried out to determine the AgNP effects on growth, reproductive output and time to the first brood, as well as the effect of different food treatments. Data for growth and reproduction were checked for normal distribution with the Shapiro-Wilk method and Levenes' test for homogeneity of variances. If criteria were met, one-way analysis of variance (ANOVA) was used to compare the effects for different silver concentrations and two-way ANOVA for comparison of different food levels and silver concentrations. If data were not normally 
distributed and had equal variances, they were rank-transformed (Akritas, 1990) before performing ANOVA. Data for time to first reproduction event were analyzed using Kaplan-Meier log-rank test. Significance for all statistical tests was assumed with $p<$ 0.05. Only data from parent animals that survived until the termination of the test were used for the statistical analysis with the exception of the cumulative time to first reproduction analysis.

\section{Results}

\subsection{AgNP characterization}

The analysis of AgNP stock suspension using TEM (Figure 1), DLS and ICP-OES were consistent with the data provided by the manufacturer. Dilutions of AgNP stock suspension in Milli-Q water showed that with lower concentrations of AgNP the polydispersity index (Pdl) was increasing (Table 1 ), which might be an indication for particle agglomeration and/or aggregation. Zeta potential measurements verified that the AgNP stock suspension was stable $(-46.9 \pm 1.3 \mathrm{mV})$, but diluted suspensions in $\mathrm{M7}$ medium showed decreased stability. Unfortunately, good quality data from samples containing AgNP suspended in M7 medium could not be obtained, most likely due to rapid agglomeration caused by the high ionic strength of the medium. The concentration of dissolved $\mathrm{Ag}$ after 3 days in M7 medium was determined to account for $3.1 \pm 0.4 \%$ of the nominal Ag content. Mass balance analysis revealed that after 3 days the actual silver concentration in the suspension was only $53 \pm 5 \%$ and $70 \pm 6 \%$ from the 
nominal concentration for low and high food treatments, respectively. Measurements of silver content in daphnids were all below the quantification limit. Amounts corresponding to $11 \pm 2 \%$ (low food) and $8 \pm 1 \%$ (high food) of nominal content of silver was found on the glass beaker walls, and the remaining silver is left as unclassifiable loss. For the sake of simplicity, nominal silver concentrations have been used for all data analysis.

\subsection{Acute toxicity of AgNP towards D. magna}

Acute toxicity test with $\mathrm{AgNO}_{3}$ yielded a 48 hour EC50 value of $0.75 \mu \mathrm{gg} / \mathrm{L}[95 \% \mathrm{Cl}$ 0.61; 0.92], which is close to the values found in the literature (Bianchini et al., 2002, Kennedy et al., 2010, Allen et al., 2010). The concentration-response curves and the 48 hour EC50 values obtained in the acute toxicity tests with AgNP clearly showed that with more food provided the toxicity was decreased (Table 2). Daphnids exposed to AgNP in high food treatments had algal cells adhered to their exoskeleton, which resulted in some immobility in lower exposure concentrations, most likely due to the difficulties to swim around and moult.

\subsection{Chronic toxicity of AgNP under different feeding conditions}

The chronic test with $\mathrm{AgNO}_{3}$ showed no significant effect $(p<0.05)$ on growth, reproduction per surviving female or days to first brood in any exposure concentration, but there was a clear effect on mortality (60\% mortality at the highest concentration of

1.6 $\mu \mathrm{g} \mathrm{Ag/L).} \mathrm{The} \mathrm{study} \mathrm{by} \mathrm{Zhao} \mathrm{and} \mathrm{Wang} \mathrm{(Zhao} \mathrm{and} \mathrm{Wang,} \mathrm{2011)} \mathrm{has} \mathrm{reported} \mathrm{very}$ 
similar results, having no effects on growth and reproduction, but $50 \%$ mortality at 1.6 $\mu \mathrm{g} / \mathrm{L}$. In our study the exposure to AgNP affected survival, growth and reproduction of D. magna with similar concentration-response patterns for both food treatments. In the case of low food treatment an increased mortality was observed for concentrations higher than $20 \mu \mathrm{g} / \mathrm{L}$, whereas for high food treatment similar effects occurred at concentrations above $40 \mu \mathrm{g} / \mathrm{L}$. Both growth and reproduction of parent $D$. magna was inhibited with increasing concentrations of AgNP (Table 3). Growth rate per surviving female is presented as difference in size of the parent animals from day 0 to day 21 . As shown in Table 3, half of parent animals in controls had died at day 21. As both tests were performed simultaneously and animals were fed the same food, it is very likely that the increased mortality was due to a bacterial infection in the algal suspension used for feeding during the last days of testing. A bacterial infection could also explain why silver exposure in lower concentrations (10 and $20 \mu \mathrm{g} / \mathrm{L}$ ) had somewhat beneficial effect on survival compared to control and that no increased mortality was observed for the exposed animals in the same time frame. However, there is a need for scientific studies to test the potential hormetic effect of low concentrations of silver. Regardless of the food treatment negative effects on growth occurred in concentrations above $10 \mu \mathrm{g} / \mathrm{L}$, but it should be noted that high variations in growth rates of individual animals were observed within each exposure concentration. Both treatments also showed a slight increase in animal size at $10 \mu \mathrm{g} / \mathrm{L}$ exposure, but it was statistically significant $(p=0.004)$ only for the low food treatment. The lowest concentration with a statistically significant $(p<0.05)$ inhibitory effect on growth was at $30 \mu \mathrm{g} / \mathrm{L}$ for both food levels. 
The growth rate of the live parent animals increased significantly $(p<0.05)$ in the high food treatment compared to low food treatment for controls and all exposure concentrations except for $30 \mathrm{\mu g} / \mathrm{L}$ exposure (Table 3). The number of offspring produced per living parent daphnid (Table 3) showed concentration-response patterns similar to that of the growth rate data. However, the cumulated number of offspring per living parent $D$. magna at day 21 varied considerably between treatments and exposure concentrations. A significant difference in the cumulated number of offspring was noted at $40 \mu \mathrm{g} / \mathrm{L}$ and $50 \mu \mathrm{g} / \mathrm{L}$ in the low food treatment as well as at 30 and $50 \mu \mathrm{g} / \mathrm{L}$ in high food treatment $(p<0.05)$. The cumulated number of offspring at $10 \mu \mathrm{g} / \mathrm{L}$ was slightly higher than what was observed for the controls for both food treatments. However, due to the high variation between the individual parent animals, this difference was not statistically significant $(p>0.05)$.

The time to first reproduction showed some variation among individual animals within the different exposure concentrations and food scenarios. When analyzing time to first brood for daphnids surviving until day 21 , on average a slight non-significant increase ( $p$ $>0.05$ ) was observed under low food conditions (Table 3 ). It should however be noted that the $D$. magna mothers included in this analysis had produced at least one clutch of live neonates during the exposure period, but there were also a few parent daphnids that survived until the end of the test without producing any offspring. When including the parent animals that did not survive until the termination of the test as well as those that were alive but did not reproduce during the test, the results provide an indication 
of how many daphnids were able to reproduce in a given treatment and AgNP exposure. Cumulative frequencies in the number of reproducing females over time were lower in the low food treatment compared to the higher food treatment (Figure 2). Furthermore, the cumulative frequencies decreased with increased exposure concentration from 20 $\mu \mathrm{g} / \mathrm{L}$ and $50 \mu \mathrm{g} / \mathrm{L}$ in low and high food, respectively (Figure 2 ).

\section{Discussion}

The acute toxicity tests showed that the addition of food to D. magna tests can have a pronounced influence on toxicity of AgNP. The 48 hour EC50 values were approximately 4-fold and 6-fold higher for low and high food treatments, respectively compared with the EC50 obtained without addition of food. This is in agreement with the findings by Allen et al. (Allen et al., 2010) who also found an almost 6-fold increase in 48 hour LC50 value for D. magna when food was supplied during AgNP exposure. In addition, this study showed that higher food availability counteracted the observed effect on survival, growth and reproduction of D. magna when exposed to AgNP under low food conditions. Plausible explanations for reduced AgNP toxicity might be decreased exposure or decreased uptake of AgNPs or Ag ions when algal food is present. Allen et al. (Allen et al., 2010) proposed that AgNP could form complexes with organic matter and thus become unavailable for uptake. However, the decreased toxicity might also be a result of complexation between the organic material in the medium and ionic silver released from the AgNP (Allen et al., 2010). This is also supported by the fact that $P$. 
subcapitata, which was used as food in this study, is known to produce exudates, which can considerably decrease toxicity of metals by complexation (Koukal et al., 2007). Moreover, experiments have shown that AgNP can adhere to algal cells (Navarro et al., 2008), which may lead to lower amounts of AgNP remaining in suspension, as a fraction of algae supplied to the test setup were sedimenting on the bottom of the beaker, making it less available for uptake by a predominantly pelagic species such as D. magna. Zhao and Wang (Zhao and Wang, 2010) have reported that ingestion of AgNP which are adsorbed to algae accounts for more than $70 \%$ of silver that accumulates in D. magna. This indicates that food is a very important route of uptake for AgNP in daphnids. However, in our study the higher abundance of food was found to decrease toxicity thus suggesting a lower availability of particles adsorbed to algae, most likely due to the observed sedimentation of algae during incubation. In addition, daphnids may adjust their food intake rate with environmental food availability (Pop, 1991, Lampert, 1994, Plath, 1998). Increased filtration rates in the absence of food or under conditions of low food availability may thus lead to increased uptake of AgNP, either as agglomerates or attached to algal particles, into the gut.

In general, the two chronic tests performed in this study showed that increasing concentrations of AgNP affect survival, growth and reproduction of $D$. magna. Similar to our findings for daphnids exposed to $10 \mu \mathrm{g} \mathrm{Ag/L,} \mathrm{Gaiser} \mathrm{et} \mathrm{al.} \mathrm{(2011)} \mathrm{found} \mathrm{an} \mathrm{increase}$ in body length at a concentration of $1 \mu \mathrm{g} \mathrm{Ag} / \mathrm{L}$. Various hypotheses have been proposed to explain this phenomenon, for example that the surviving $D$. magna may be the fittest 
and therefore more likely to grow larger, or that an adaptation/tolerance of the daphnids to metal exposure includes metabolic changes favoring growth (Gaiser et al., 2011). Higher AgNP exposure concentrations lead to reduced growth and reproduction in a dose-response manner. Decreased cumulative offspring was observed also in studies by Zhao and Wang (2011) and Blinova et al. (2013) at AgNP exposures of 50 and $100 \mu \mathrm{g} / \mathrm{L}$, respectively. Reduced reproductive output can be partly ascribed to reduced growth as egg numbers depend on the size of parent daphnids (Blinova et al., 2013). However, this can probably not explain the full magnitude of reproductive decline observed in our experiments and additional effects on reproduction have to be taken into account.

Cumulated number of females reproducing (Figure 2) illustrates that both AgNP exposure and food abundance significantly influence the daphnids' ability to survive and reproduce. At low food conditions, daphnids exposed to AgNP can still survive, but do not produce any offspring at the highest AgNP concentration (Table 3). In contrast, daphnids exposed to the same AgNP exposure concentrations in the high food treatment were still able to reproduce even at $50 \mu \mathrm{g} / \mathrm{L}$, indicating that higher food availability may benefit population fitness under AgNP exposure. Surviving individuals that are not able to reproduce can be considered dead in an ecological sense, since they will not contribute to population sustainability or growth. Obviously, when either reproduction or juvenile survival ceases completely a migrationally isolated population will become extinct regardless of the effect on other individual life history traits (e.g., 
(Linke-Gamenick et al., 2000)). When juvenile mortality and reproductive inhibition is less than $100 \%$, the relative importance of changes in different individual life-history traits (e.g., caused by contaminants) on population growth and sustainability varies with e.g., lifecycle type. This makes it difficult to predict population level impacts of contaminants directly from individual level effects without integrating observed effects on life history traits into a population model. However, in a study by Forbes et al. (2010) the authors showed that for D. magna fecundity was consistently (i.e., in 26 out of the 26 selected cases) the least elastic life history trait. This means that even relatively large effects on reproductive output had relatively low impacts on population growth rate, whereas the opposite was the case for juvenile survival.

To the best of our knowledge, this is the first study to present AgNP chronic toxicity depending on food availability. However, the question regarding effects of food in the absence of toxicants has already been addressed in the literature by conducting experiments that were lasting the whole life cycle of $D$. magna with different food levels (Martínez-Jerónimo et al., 1994). The life span of D. magna is up to 100 days under favorable conditions (Preuss et al., 2009). Martínez-Jerónimo et al. (1994) showed that higher amounts of food supplied led to increased growth and reproduction rates. They also noted that animals exposed to high food abundance died earlier than the ones exposed to medium food treatment. The ultimate size and cumulative reproductive output ended up being the same for both food treatments. That raises the question whether 21 days are enough to reveal the actual chronic toxicity of AgNP. Performing 
toxicity tests that cover the whole life cycle of $D$. magna would provide results that could possibly reveal whether the ultimate size and cumulative reproductive output change with different food treatments under AgNP exposure. However, a major drawback for conducting a whole life cycle experiment is that it is very time consuming and resource demanding.

\section{Conclusion}

This study aimed to investigate what effects food availability may have on chronic toxicity of AgNP to D. magna. For the two 21 day tests a dose-response relationship was observed for mortality, growth and reproduction. The high food treatment lowered observed detrimental effects of AgNP on animal survival, growth rate and reproductive output in comparison to low food treatment, likely due to alterations in exposure or toxicokinetics depending on food density. This study has shown that there are perspectives for future research to obtain better understanding about chronic toxicity of AgNP. For instance, additional information on bioaccumulation of AgNP in D. magna would be needed to understand various toxic effects.

\section{Acknowledgements}

The study was funded by the European Research Council Starting Grant "EnvNano" (ERC Grant no. 281579). Contribution of André Gergs and Annemette Palmqvist was financially supported by the European Union (project no 266712: ModNanoTox). We sincerely thank our lab technicians Signe Qualmann and Susanne Kruse for their 
contribution to this work.

\section{References}

Akritas, M.G., 1990. The rank transform method in some two-factor designs. Journal of the American Statistical Association 85, 73-78.

Allen, H.J., Impellitteri, C.A., Macke, D.A., Heckman, J.L., Poynton, H.C., Lazorchak, J.M., Govindaswamy, S., Roose, D.L., Nadagouda, M.N., 2010. Effects from filtration, capping agents, and presence/absence of food on the toxicity of silver nanoparticles to Daphnia magna. Environmental Toxicology and Chemistry 29, 2742-2750.

Baun, A., Hartmann, N.B., Grieger, K., Kusk, K.O., 2008. Ecotoxicity of engineered nanoparticles to aquatic invertebrates: a brief review and recommendations for future toxicity testing. Ecotoxicology 17, 387-395.

Bianchini, A., Bowles, K.C., Brauner, C.J., Gorsuch, J.W., Kramer, J.R., Wood, C.M., 2002. Evaluation of the Effect of Reactive Sulfide on the Acute Toxicity of Silver (I) to Daphnia magna. Part 2: Toxicity Results. Environmental Toxicology and Chemistry 21, 1294-1300.

Bianchini, A., Wood, C.M., 2008. Does sulfide or water hardness protect against chronic silver toxicity in Daphnia magna? A critical assessment of the acute-to-chronic toxicity ratio for silver. Ecotoxicology and Environmental Safety 71, 32-40. 
Blinova, I., Niskanen, J., Kajankari, P., Kanarbik, L., Kakinen, A., Tenhu, H., Penttinen, O., Kahru, A., 2013. Toxicity of two types of silver nanoparticles to aquatic crustaceans Daphnia magna and Thamnocephalus platyurus. Environmental Science and Pollution Research International 20, 3456-3463.

Christensen, E.R., Kusk, K.O., Nyholm, N., 2009. Dose-response regressions for algal growth and similar continuous endpoints: Calculation of effective concentrations. Environmental Toxicology and Chemistry 28, 826-835.

Cupi, D., Hartmann, N.B., Baun, A., 2015. The influence of natural organic matter and aging on suspension stability in guideline toxicity testing of $\mathrm{Ag}, \mathrm{ZnO}$, and $\mathrm{TiO} 2$ nanoparticles with Daphnia magna. Environmental Toxicology and Chemistry (in press).

Elzey, S., Grassian, V.H., 2010. Agglomeration, isolation and dissolution of commercially manufactured silver nanoparticles in aqueous environments. Journal of Nanoparticle Research 12, 1945-1958.

Forbes, V.E., Olsen, M., Palmqvist, A., Calow, P., 2010. Environmentally sensitive lifecycle traits have low elasticity: implications for theory and practice. Ecological Applications 20, 1449-1455.

Gaiser, B.K., Biswas, A., Rosenkranz, P., Jepson, M.A., Lead, J.R., Stone, V., Tyler, C.R., Fernandes, T.F., 2011. Effects of silver and cerium dioxide micro- and nano-sized particles on Daphnia magna. Journal of Environmental Monitoring 13, 1227-1235. 
Gaiser, B.K., Fernandes, T.F., Biswas, A., Rosenkranz, P., Stone, V., Jepson, M.A., Britton, G.J., Lead, J.R., Baalousha, M., Cole, P.A., Ju-Nam, Y., Tyler, C.R., Johnston, B.D., Scown, T.M., 2012. Interspecies comparisons on the uptake and toxicity of silver and cerium dioxide nanoparticles. Environmental Toxicology and Chemistry 31, 144-154.

Hailing-Sørensen, B., Nyhohn, N., Baun, A., 1996. Algal toxicity tests with volatile and hazardous compounds in air-tight test flasks with $\mathrm{CO} 2$ enriched headspace.

Chemosphere 32, 1513-1526.

Hoheisel, S.M., Diamond, S., Mount, D., Hoheisel, S.M., 2012. Comparison of nanosilver and ionic silver toxicity in Daphnia magna and Pimephales promelas. Environmental Toxicology and Chemistry 31, 2557-2563.

Kennedy, A.J., Hull, M.S., Bednar, A.J., Goss, J.D., Gunter, J.C., Bouldin, J.L., Vikesland, P.J., Steevens, J.A., 2010. Fractionating Nanosilver: Importance for Determining Toxicity to Aquatic Test Organisms. Environmental Science and Technology 44, 9571-9577.

Koukal, B., Rosse, P., Reinhardt, A., Ferrari, B., Wilkinson, K.J., Loizeau, J., Dominik, J., 2007. Effect of Pseudokirchneriella subcapitata (Chlorophyceae) exudates on metal toxicity and colloid aggregation. Water Research 41, 63-70.

Lampert, W., 1994. Phenotypic plasticity of the filter screens in Daphnia: Adaptation to a low-food environment. Limnology and Oceanography 39, 997-1006. 
Linke-Gamenick, I., Forbes, V.E., Méndez, N., 2000. Effects of chronic fluoranthene exposure on sibling species of Capitella with different development modes. Marine Ecology Progress Series 203, 191-203.

Martínez-Jerónimo, F., Villaseñor, R., Rios, G., Espinosa, F., 1994. Effect of food type and concentration on the survival, longevity, and reproduction of Daphnia magna. Hydrobiologia 287, 207-214.

McCauley, E., Murdoch, W.W., 1987. Cyclic and stable populations: plankton as paradigm. American Naturalist, 97-121.

McCauley, E., Nisbet, R.M., Murdoch, W.W., de Roos, A.M., Gurney, W.S., 1999. Largeamplitude cycles of Daphnia and its algal prey in enriched environments. Nature 402, 653-656.

Miller, R.S., 1967. Pattern and process in competition. Advances in ecological research 4, $1-74$.

Moore, M., 2006. Do nanoparticles present ecotoxicological risks for the health of the aquatic environment? Environment International 32, 967-976.

Navarro, E., Piccapietra, F., Wagner, B., Marconi, F., Kaegi, R., Odzak, N., Sigg, L., Behra, R., 2008. Toxicity of Silver Nanoparticles to Chlamydomonas reinhardtii. Environmental Science and Technology 42, 8959-8964. 
Organisation for Economic Co-operation and Development, 2012. Test No. 211. Daphnia magna Reproduction Test. OECD Guideline for Testing of Chemicals. Paris, France.

Organisation for Economic Co-operation and Development, 2004. Test No. 202. Daphnia sp., Acute Immobilisation Test. OECD Guideline for Testing of Chemicals. Paris, France.

Plath, K., 1998. Adaptive feeding behavior of Daphnia magna in response to short-term starvation. Limnology and Oceanography 43, 593-599.

Pokhrel, L.R., Dubey, B., 2012. Potential Impact of Low-Concentration Silver Nanoparticles on Predator:Prey Interactions between Predatory Dragonfly Nymphs and Daphnia magna as a Prey. Environmental Science and Technology 46, 7755-7762.

Pop, M., 1991. Mechanisms of the filtering area adaptation in Daphnia, in Anonymous Biology of Cladocera. Springer, pp. 169-176.

Porter, K., Orcutt Jr, J., Gerritsen, J., 1983. Functional response and fitness in a generalist filter feeder, Daphnia magna (Cladocera: Crustacea). Ecology, 735-742.

Poynton, H.C., Lazorchak, J.M., Impellitteri, C.A., Blalock, B.J., Rogers, K., Allen, H.J., Loguinov, A., Heckman, J.L., Govindasmawy, S., 2012. Toxicogenomic Responses of Nanotoxicity in Daphnia magna Exposed to Silver Nitrate and Coated Silver Nanoparticles. Environmental Science and Technology 46, 6288-6296. 
Preuss, T.G., Hammers-Wirtz, M., Hommen, U., Rubach, M.N., Ratte, H.T., 2009.

Development and validation of an individual based Daphnia magna population model:

The influence of crowding on population dynamics. Ecological Modelling 220, 310-329.

Ratte, H.T., 1999. Bioaccumulation and Toxicity of Silver Compounds. Environmental Toxicology and Chemistry 18, 89-108.

Roemer, I., White, T.A., Baalousha, M., Chipman, K., Viant, M.R., Lead, J.R., 2011.

Aggregation and dispersion of silver nanoparticles in exposure media for aquatic toxicity tests. Journal of Chromatography A 1218, 4226-4233.

Shafer, M.M., Overdier, J.T., Armstrong, D.E., 1998. Removal, partitioning, and fate of silver and other metals in wastewater treatment plants and effluent-receiving streams. Environmental Toxicology and Chemistry 17, 630-641.

The Project on Emerging Nanotechnologies (PEN), 2013. Available from: http://www.nanotechproject.org/.

Zhao, C., Wang, W., 2010. Biokinetic uptake and efflux of silver nanoparticles in Daphnia magna. Environmental Science and Technology 44, 7699-7704.

Zhao, C., Wang, W., 2011. Compatison of acute and chronic toxicity of silver nanoparticles and silver nitrate to Daphnia magna. Environmental Toxicology and Chemistry 30, 885-892. 


\section{TABLES AND FIGURES}

Table 1: AgNP hydrodynamic diameter $(\mathrm{nm})$ and suspension stability (zeta potential, $\mathrm{mV}$ ) in Milli-Q water, M7 medium, and undiluted stock suspension $(n=3)$. HDD:

Hydrodynamic diameter; Pdl: Polydispersity index.

Table 2: Food treatments ( $P$. subcapitata) and 24 and 48 hour EC50 values for AgNP acute toxicity tests with D. magna. $95 \%$ confidence intervals are shown in brackets.

Table 3: Exposure concentrations and toxicity endpoints for Daphnia magna after exposure to different food levels for 21 days. Mean \pm standard deviations are shown for living animals (initially 10 animals were used for each concentration and controls). *Significantly different from control $(p<0.05)$; † Significantly different from high food level $(p<0.05)$

Figure 1: TEM image of AgNP stock solution.

Figure 2: Cumulative frequencies for D. magna that were reproducing as a function of exposure time for different concentrations of AgNP. Low food: Approximately $2.4 \times 10^{5}$ cells/mL; High food: Approximately $7.2 \times 10^{5}$ cells $/ \mathrm{mL}$. 
Table 1:

\begin{tabular}{|c|c|c|c|c|c|}
\hline & \multirow{2}{*}{$\begin{array}{c}\text { Conc. } \\
(\mu \mathrm{g} \mathrm{Ag} / \mathrm{L})\end{array}$} & \multicolumn{2}{|c|}{ HDD by volume $(\mathrm{nm})$} & \multirow{2}{*}{$\mathrm{Pdl}$} & \multirow{2}{*}{$\begin{array}{c}\text { Zeta potential } \\
(\mathrm{mV})\end{array}$} \\
\hline & & Peak 1 & $\%$ & & \\
\hline Stock & 20000 & $34.0 \pm 1.2$ & 100 & $0.145 \pm 0.035$ & $-46.9 \pm 1.3$ \\
\hline \multirow[t]{4}{*}{ Milli-Q } & 1000 & $35.8 \pm 0.2$ & 100 & $0.192 \pm 0.010$ & $-55.2 \pm 1.9$ \\
\hline & 100 & $34.5 \pm 0.5$ & 100 & $0.173 \pm 0.003$ & $-27.4 \pm 5.1$ \\
\hline & 50 & $33.6 \pm 0.7$ & 98 & $0.250 \pm 0.034$ & $-26.9 \pm 11.6$ \\
\hline & 10 & $33.8 \pm 4.7$ & 94 & $0.243 \pm 0.055$ & $-15.7 \pm 3.7$ \\
\hline \multirow[t]{3}{*}{ M7 } & 100 & $55.4 \pm 4.5$ & 100 & $0.180 \pm 0.011$ & $-8.56 \pm 0.76$ \\
\hline & 50 & $48.2 \pm 2.9$ & 100 & $0.248 \pm 0.006$ & $-13.3 \pm 0.23$ \\
\hline & 10 & $44.5 \pm 1.2$ & 100 & $0.487 \pm 0.004$ & $-6.72 \pm 1.5$ \\
\hline
\end{tabular}

Table 2:

\begin{tabular}{llll}
\hline Treatment & $\begin{array}{l}\text { Food } \\
(\text { cells } / \mathrm{mL})\end{array}$ & $\begin{array}{l}24 \mathrm{~h} \mathrm{EC50} \\
(\mu \mathrm{g} \mathrm{Ag} / \mathrm{L})\end{array}$ & $\begin{array}{l}48 \mathrm{~h} \mathrm{EC50} \\
(\mu \mathrm{g} \mathrm{Ag} / \mathrm{L})\end{array}$ \\
\hline No food & - & $61.2[61.2 ; 61.2]$ & $47.6[47.6 ; 47.6]$ \\
Low food & $2.4 \times 10^{5}$ & $200[197 ; 204]$ & $184[178 ; 191]$ \\
High food & $7.2 \times 10^{5}$ & $304[297 ; 313]$ & $302[210 ; 436]$ \\
\hline
\end{tabular}

Table 3:

\begin{tabular}{llllll}
\hline $\begin{array}{l}\text { Food } \\
\text { treatment } \\
\text { (cells } / \mathrm{mL} \text { ) }\end{array}$ & $\begin{array}{l}\text { AgNP conc. } \\
(\mu \mathrm{g} \mathrm{Ag} / \mathrm{L})\end{array}$ & $\begin{array}{l}\text { Survival } \\
(\%)\end{array}$ & $\begin{array}{l}\text { Time to first } \\
\text { brood (d) }\end{array}$ & $\begin{array}{l}\text { Cumulative offspring } \\
\text { per living parent }\end{array}$ & $\begin{array}{l}\text { Growth from day 0 } \\
\text { to 21 }(\mathrm{mm})\end{array}$ \\
\hline $2.4 \times 10^{5}$ & Control & 50 & $8.6 \pm 0.7$ & $82.0 \pm 23.2$ & $2.91 \pm 0.18^{+}$ \\
$($Low $)$ & 10 & 60 & $8.6 \pm 0.9$ & $110.5 \pm 18.0$ & $3.18 \pm 0.12^{*^{+}}$ \\
& 20 & 80 & $9.7 \pm 1.5$ & $58.0 \pm 39.1^{+}$ & $2.68 \pm 0.47^{\dagger}$ \\
& 30 & 50 & $9.8 \pm 0.5$ & $35.6 \pm 32.6$ & $2.61 \pm 0.18^{*}$ \\
& 40 & 20 & $11^{*}$ & $1.0^{*+}$ & $2.62^{*^{+}}$ \\
& 50 & 20 & - & $0^{*}$ & $2.27^{*^{+}}$ \\
\hline $7.2 \times 10^{5}$ & Control & 50 & $8.5 \pm 0.9$ & $136.0 \pm 26.3$ & $3.48 \pm 0.21$ \\
$($ High) & 10 & 80 & $7.8 \pm 0.9$ & $153.6 \pm 28.4$ & $3.64 \pm 0.20$ \\
& 20 & 100 & $9.0 \pm 1.6$ & $121.6 \pm 21.1$ & $3.36 \pm 0.09$ \\
& 30 & 90 & $9.8 \pm 2.0$ & $73.6 \pm 22.5^{*}$ & $2.82 \pm 0.20^{*}$ \\
& 40 & 90 & $8.8 \pm 1.4$ & $100.6 \pm 27.5$ & $3.12 \pm 0.13^{*}$ \\
& 50 & 40 & $9.4 \pm 1.7$ & $31.5 \pm 29.1^{*}$ & $2.94 \pm 0.17^{*}$ \\
\hline
\end{tabular}


Figure1:

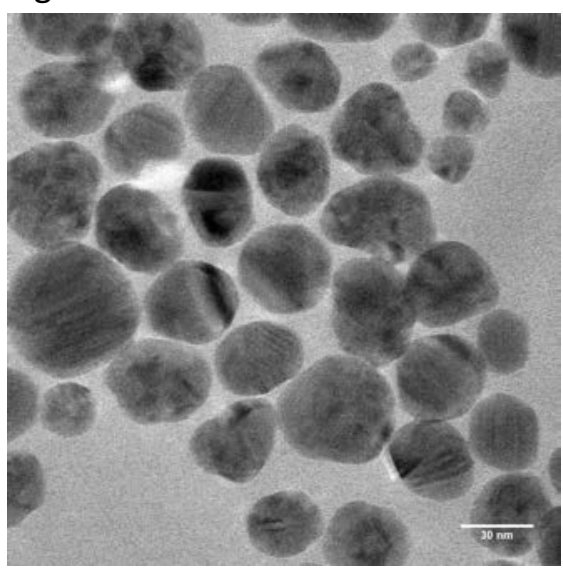

Figure 2:
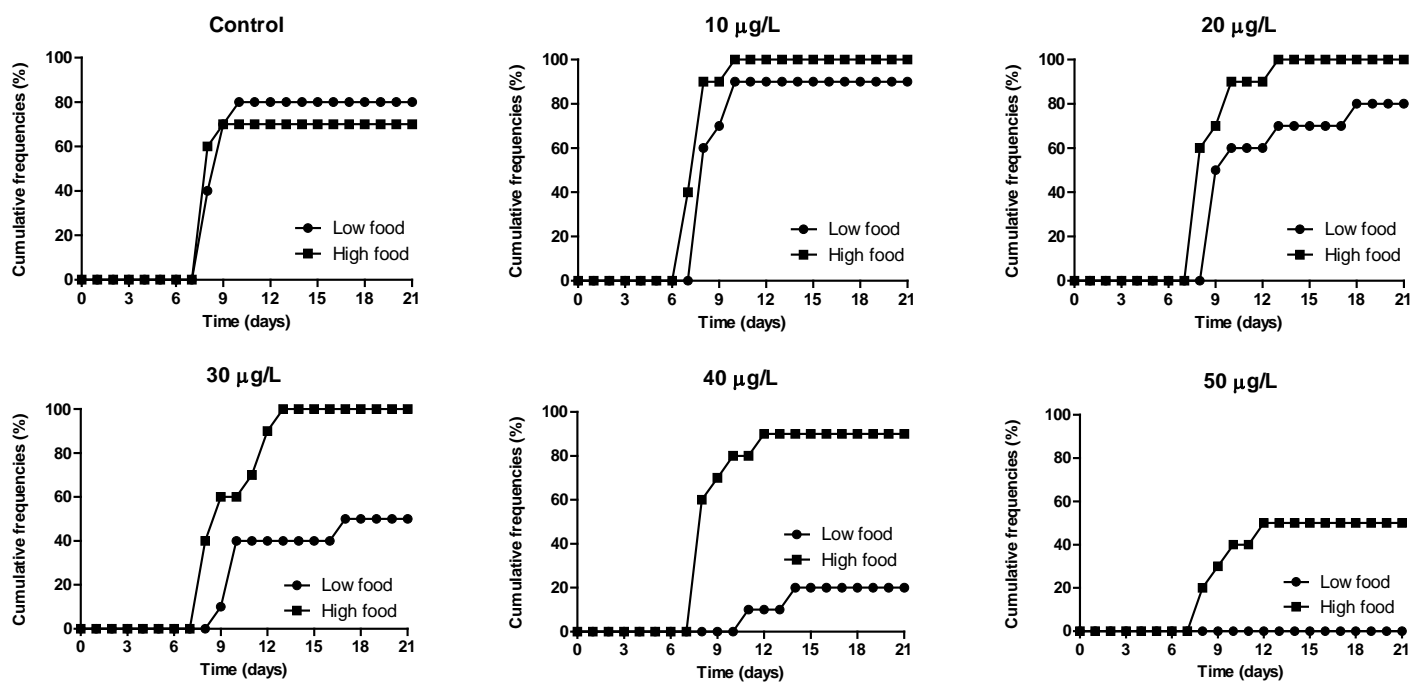